\title{
Silencio y metáfora en Ramón Gaya
}

\section{RESUMEN:}

Este artículo propone la lectura de dos poemas escritos por Ramón Gaya, bajo el influjo del acontecimiento que marcó un punto de inflexión en la evolución de su obra, a saber: su regreso a Europa, el descubrimiento de Venecia y su decisión de instalarse definitivamente en Italia. Al considerar a Gaya como un pintor que escribe, se aprecia con claridad que sus escritos y sus pinturas se reflejan y se complementan. Aquí el diálogo entre sus poemas y su pintura permite localizar metáforas, analogías y alegorías, claves en la interpretación de su obra, tanto pictórica como escrita.

\section{PALABRAS CLAVE:}

Concavidad, encarnación, espera, principio, quietud, vacío.
Miriam Moreno Aguirre

Doctora en Filosofía por la UCM y ensayista

\begin{abstract}
:
This article proposes the reading of two poems by Ramón Gaya, written under the influence of the event, which marked a turning point in the evolution of his work, namely: his return to Europe, the discovery of Venice and his decision to settle permanently in Italy. By viewing Gaya as a painter who writes, it is clear that his writings and paintings reflect and complement each other. This dialogue between his poems and his painting allows us to locate the metaphors, analogies and allegories, key in the interpretation of his work, both pictorial and written.
\end{abstract}

\section{KEYWORDS:}

Concavity, incarnation, waiting, beginning, stillness, emptiness.

Como es sabido, el pintor murciano Ramón Gaya, uno de los republicanos españoles que partieron en el barco Sinaia, se propuso poner fin a su exilio mexicano a partir de 1952, cuando vino a Europa camino de Italia. El descubrimiento de Venecia supuso un punto de inflexión en la evolución de su obra. A Italia regresó ya definitivamente de México en 1956 y se estableció en Roma, donde trató con asiduidad a María Zambrano, que a su vez le introdujo en el círculo de la escritora 
Elena Croce, hija del filósofo Benedetto $\mathrm{Croce}^{1}$. Su estancia italiana fue de intensa vida intelectual. Durante ese tiempo abordó el cuadro de tema y su apuesta por la pintura como encarnación de lo real, un reto pictórico descomunal, que podía parecer casi una provocación o un gigantesco malentendido, como él mismo pudo constatar en su primera exposición de 1960, en la galería Mayer, cuando por fin regresa a España después de veintiún años de exilio. José Bergamín pronunció unas palabras el día de la inauguración, pero como observa Juan Manuel Bonet: «no era aquel un momento madrileño muy adecuado para que se apreciara el tipo de pintura que Gaya hacía, ni el tipo de actitud hacia el arte que propugnaba. El muro de silencio, por parte sobre todo de la crítica más militantemente vanguardista, fue tremendo» (Bonet, 2005: 18). Quizá este desencuentro con el mundo de la cultura española en su regreso a Madrid después de tantos años fue una de las principales razones por las que nunca puso del todo fin a su peregrinaje, ya que alternó temporadas en España con otras en París, Aix-en-Provence, Venecia o Florencia, sin perder de vista Roma, que había sido su ciudad estable. Fue allí donde vivió sus últimos años de exiliado y donde mantuvo abierta su casa-estudio en la que llevó a cabo algunas de sus obras mayores.

En 1959 Gaya escribió El sentimiento de la pintura, traducido al italiano un año después por Leonardo Cammarano (Gaya, 1960a). Recientemente, fue de nuevo publicado en Italia con traducción de Laura Mariateresa Durante (Gaya, 2015). El ensayo nace del hechizo que provoca en él Venecia y de su fascinación por las obras de los maestros venecianos. En aquellos años culmina una fase de maduración creadora iniciada al comienzo del exilio. Sobre sus estancias en Venecia, Gaya ha dejado anotaciones en el Diario de un pintor (2010: 395), tanto de su primer viaje en 1952 en compañía de Juan Gil-Albert, Concha Albornoz y su amiga Clara James, como de su segundo y definitivo viaje a Europa en 1956. También dejó constancia en su diario de sus escapadas desde Roma a la Serenissima -como a él le gustaba llamarla-, impresiones que encontramos igualmente en Cartas a sus amigos (2016).

En 1970, junto al Campo de' Fiori, cercano al palazzo Farnese y a la Via Giulia, Gaya adquirió un estudio en el Vicolo del Giglio, donde pasaba largas temporadas estivales pintando y escribiendo. Su relación más cercana y asidua desde 1956 hasta 1965 fue la que mantuvo con María Zambrano, a quien le unían lazos de afecto e intelectuales, que se habían ido estrechando desde los días de las Misiones

\footnotetext{
${ }^{1}$ Allí conoció a personalidades como Italo Calvino, Alberto Moravia, Natalia Ginzburg, Nicola Chiaromonte, Pietro Citati, Elémire Zolla, Cristina Campo y Leonardo Cammarano. Igualmente conoció al escultor Giacomo Manzú y al valenciano Carmelo Pastor, becado en la Academia de Roma, al que trató con asiduidad, así como al poeta Enrique de Rivas, sobrino de Manuel Azaña. Posteriormente entabló amistad con el filósofo Giorgio Agamben, a quien prestó su estudio de Roma durante unos años. Véase J. Muñoz Millanes, La Venecia de Ramón Gaya (2015).
} 
Pedagógicas y la revista Hora de España, quizá las empresas culturales más relevantes de la Segunda República, en las que ambos fueron activos colaboradores. Testimonio de su cercana amistad es, además de su diario, el epistolario $Y$ así nos entendimos (2018). Por su parte, la filósofa escribió textos fundamentales sobre las obras del pintor (2012). En 1971 se publicó en italiano y en Italia Velázquez, pájaro solitario, considerado su ensayo mayor, que fue galardonado con el premio Inedito. Mientras se lo permitió su salud y hasta los noventa años, Ramón Gaya siguió disfrutando de largas temporadas en su estudio de Roma, donde pintó algunos de sus cuadros más emblemáticos. En definitiva, se puede concluir que Italia fue para él su segunda patria.

Muchos de los cuadros pintados en Italia entre los años 1956 y 1960 fueron expuestos en la citada galería Mayer de Madrid. En la muestra se incluían veintidós óleos, dieciocho pasteles, treinta y un gouaches y catorce dibujos (1960b). Uno de esos óleos era La pintura surgiendo del agua de Venecia, una obra cuyo rastro se ha perdido. Sobre esta alegoría hay documentado un gouache de 1958, titulado El nacimiento de la pintura [fig. 1], en el que vemos a una figura femenina emergiendo de unas aguas que bien podrían ser las de un canal veneciano.

Esta imagen preludia lo que Gaya escribió un año después en El sentimiento de la pintura: «Un atardecer, de entre aquellas aguas espesas, usadas, me pareció ver salir, surgir como una Venus cochambrosa, el manchado cuerpo de la Pintura» (2010: 43). Otros cuadros que igualmente podían verse en esta exposición eran $L a$ sed y La pintura ofreciendo agua a sus protegidos. Cuadros de tema ${ }^{2}$ sobre el motivo del agua que, como sabemos, es la metáfora gayesca de la génesis de la pintura, sin olvidar la significativa alusión a la sed y a la mujer³. Sobre la mujer y el agua hay un dibujo de 1950, titulado Mujer sacando agua del pozo, y un óleo de 1960, donde La Samaritana ofrece a Jesús de Nazaret el agua fresca del pozo, así como un gouache, Lavandera en el Tajo, de 1961, ya posterior a la exposición. El motivo del cuerpo de la mujer y su trato cotidiano con el agua es una constante de la obra de Gaya. Otras metáforas e imágenes alegóricas de la pintura y analogías se pueden reconocer en su escritura, tanto en poesía como en prosa. Es llamativo constatar hasta qué punto

\footnotetext{
${ }^{2}$ Gaya aborda el cuadro de tema -lo más difícil de pintar, según él decía-, a partir de la revolución que produjo en él su encuentro en Venecia con la maestría y la grandiosidad de la pintura de Tiziano y de Tintoretto, que no le tenían miedo ni a los temas clásicos de la literatura, de la mitología, ni a los temas religiosos. Véase Ramón Gaya (2007: 192 y 357).

${ }^{3}$ Gaston Bachelard indica que la mujer es el ideal de la naturaleza humana y «el ideal que el hombre plantea ante sí mismo como el Otro esencial, y lo feminiza porque la mujer es la figura sensible de la alteridad; por eso casi todas las alegorías, en el lenguaje como en la iconografía, son mujeres». Véase G. Bachelard, La poética de la ensoñación (2002: 58). Por otra parte, el mismo autor destaca que la imagen material del agua es esencialmente femenina. Véase Gaston Bachelard, El agua y los sueños (2002: 27).
} 


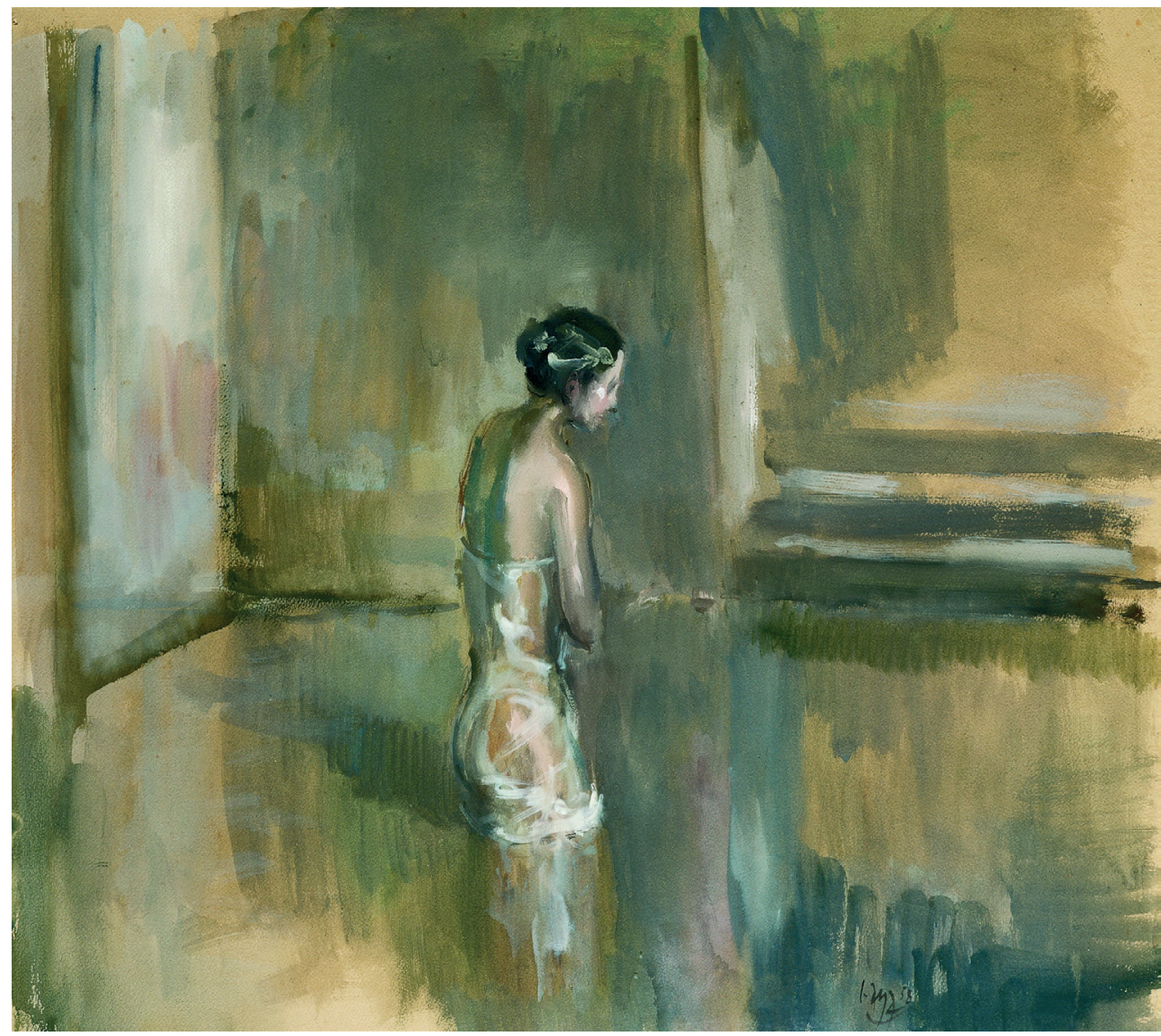

Fig. 1. El nacimiento de la pintura (1958) [gouache]

desde los comienzos de su trayectoria, su pintura y su escritura están estrechamente relacionadas. De hecho, Ramón Gaya se definía a sí mismo como «un pintor que escribe» (2007: 31 y 384) y en su diario daba cuenta de su vida como pintor, del pintar que era su verdadera vocación. Aunque él, por otra parte, sostenía que su intención no era teorizar ni se consideraba propiamente un ensayista, lo cierto es que publicó tres magníficos libros de ensayo: los dos ya mencionados El sentimiento de la pintura de 1960, Velázquez, pájaro solitario de 1969 y el tercero Naturalidad del arte y artificialidad de la crítica de 1996. Afirmaba que escribía, sencillamente, para aclararse a sí mismo sus «sospechas» y poner cierto orden a sus meditaciones. Sus escritos nos muestran dos facetas suyas: la del creador de una inmensa obra 
pictórica y la del contemplador de mirada privilegiada que cultiva el amor por las artes. Giorgio Agamben lo dice con claridad: «se puede afirmar de los escritos de Gaya lo que se ha afirmado de los aforismos de Nietzsche; a saber, que aunque son asistemáticos y fragmentarios, contienen más rigor que muchos tratados de estética» (2006: 49). Un rigor y una coherencia verificables tanto en sus pinturas como en sus escritos que dialogan, se interpelan, se reflejan y se complementan a la luz de esa otra modernidad que él defendió.

De 1927 son los cuatro poemas en prosa de un jovencísimo Ramón Gaya con dieciséis años, publicados en la revista Verso y Prosa ${ }^{4}$. A partir de aquí siguió cultivando la poesía no solo como lector o amigo de poetas ${ }^{5}$ sino también como verdadero poeta él mismo, autor de notables poemas ${ }^{6}$. De su poesía nos interesan ahora los versos motivados por el sentimiento pictórico a partir de la experiencia italiana, como este soneto de 1974, escrito en Roma y titulado «El Tevere a su paso por Roma» (2010: 628):

El Tevere se extiende como el brazo de una madre cansada y perezosa; sus aguas son de carne entreverdosa y es blando el ademán, antiguo el trazo

de esa línea curvada de su abrazo; no es un río presente, es una fosa, es una tumba viva y temblorosa que va hundiéndolo todo en su regazo;

y el pescador inmóvil, silencioso, el froccio casi lírico, la rata repentina, las putas ambulantes, un pájaro saltando, un cane ocioso, un lujo de basuras -vidrio, lata-, le bordan dos orillas delirantes.

\footnotetext{
${ }^{4}$ Ramón Gaya, «Maternidad falsa; Mañanas blancas; Tarde; Viaje», Verso y Prosa. Boletín de la joven Literatura, n. ${ }^{\circ}$ 7, Murcia, julio de 1927, p. 1, en Obra completa, «Poemas en prosa» (2010: 328-329).

${ }^{5}$ Gaya frecuentó a los poetas Juan Ramón Jiménez, Luis Cernuda, José Bergamín, Jorge Guillén y otros poetas de la Generación del 27. En México trató a Octavio Paz y a Tomás Segovia, a quién le unió una estrecha amistad. Años más tarde frecuentó igualmente a Francisco Brines, Eloy Sánchez Rosillo, Juan Manuel Bonet, José Rubio Fresneda y Andrés Trapiello, entre otros.

${ }^{6}$ Ramón Gaya, «Algunos poemas» y «Otros poemas» (2010: 613 y 643). Existe una selección de Andrés Trapiello en Algunos poemas (1991).
} 
Se diría que esta imagen de las aguas de carne «entreverdosa» del río, como el brazo de una madre que todo lo hunde en su regazo, alude al poderío de la pintura para abrazar y encarnar lo real. De este modo el Tíber no es únicamente un cauce fluvial, sino una fosa o «tumba viva», expresión que abarca dos sentidos tan opuestos como muerte y vida. Las dos figuras, el pescador silencioso e inmóvil y el froccio $^{7}$ casi lírico, junto con los otros habitantes del entorno, bordan, adornan, perfilan las dos orillas, márgenes cochambrosos y descuidados del río. Pero en el centro del poema está la imagen del río como el regazo cóncavo de la madre, y la alusión a la inmovilidad y el silencio, algunas claves de la poética que comparten la pintura y los escritos de Gaya. Así lo sugiere un cuadro suyo que parece remitir al poema. Se trata del óleo de 1979 Castel Sant'Angelo [fig. 2], en el que aparece en primer término un pescador solitario e inmóvil, silencioso y esperante ante el reflejo del castillo en las aguas del Tíber, cuya imagen está vuelta del revés, como si se estuviera hundiendo en su cauce, la cavidad que es como el regazo, según define la palabra «regazo» el diccionario de la RAE: «cavidad que forma, entre la cintura y las rodillas, la falda de una persona sentada».

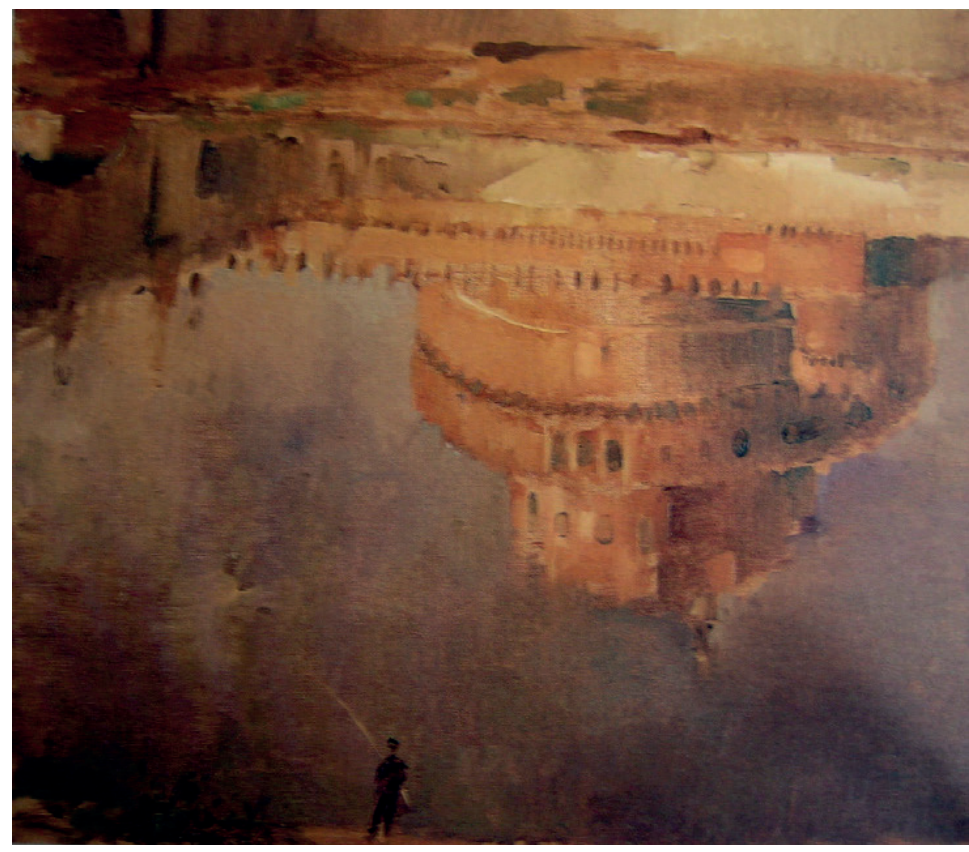

Fig. 2. Castel Sant'Angelo (1979) [gouache]

\footnotetext{
${ }^{7}$ Homosexual en italiano.
} 
Precisamente, una de las insistencias de Gaya es el motivo de la mujer sentada. Hay una acuarela extraordinaria de 1927, titulada Mujer sentada [fig. 3] en la que vemos, en efecto, a una mujer madura que descansa en una modesta silla de madera, y cuya actitud podría expresar la natural relajación en un entorno íntimo, con la barbilla apoyada sobre la mano izquierda, mientras la otra mano reposa indolente en su regazo.

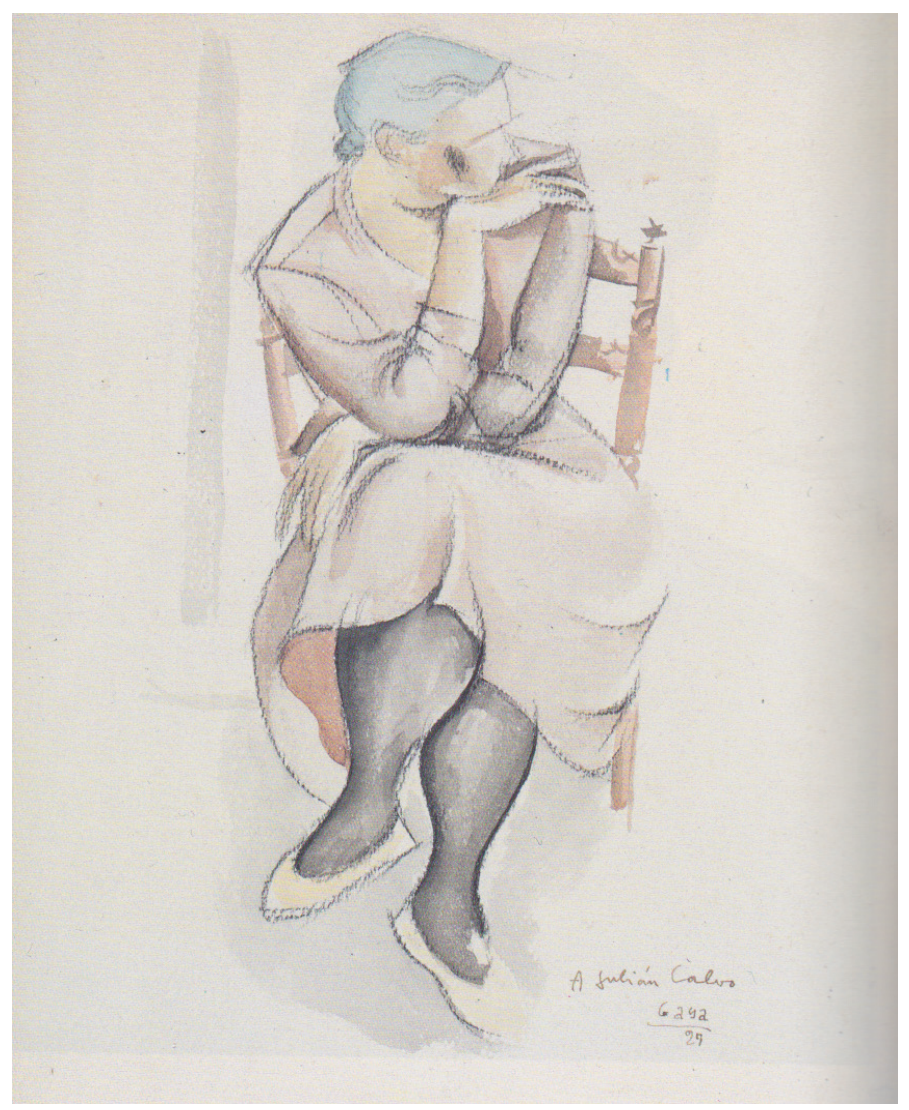

Fig. 3. Mujer sentada (1927) [acuarela]

Es indudable que esta acuarela tenía una significación especial para el pintor, ya que aparece también en el Homenaje a una acuarela de 1927, de 1987. Especial significación y gran valor afectivo porque se trata del retrato de su madre, Josefa Pomés, pintado un año antes de que ella muriera, en septiembre de 1928, cuando él 
no había cumplido aún los 18 años $^{8}$. Y Ramón, su único hijo, sentía por ella verdadera devoción, como leemos en esta anotación de 1961 en Roma: «Mi madre no era para mí una persona, sino un lugar, un lugar seguro; perdido ese lugar, uno va dando bandazos de un sitio a otro, sin sitio, sin dónde caernos muertos. Todo el terror de la muerte desaparecería si pudiéramos morir en los brazos de nuestra madre; sería ése en el momento que más necesitaríamos tenerla a nuestro lado» (2010: 593; las cursivas son de Gaya). Los brazos de la madre son el lugar hospitalario al que anhela retornar el hijo para cobijarse en el temido instante de la muerte. Cabría pensar que la imagen recuerda a la Piedad, o la Pietà en italiano, la iconografía renacentista de la Virgen María que sostiene en su regazo al hijo muerto. La más célebre es probablemente el grupo escultórico que está en la Basílica de San Pedro del Vaticano, realizado en mármol por Miguel Ángel. Hay otras obras maestras sobre la Pietà, como el último cuadro de Tiziano, al que Gaya consideraba junto con Las Meninas su pintura favorita, tal como decía en una carta desde Venecia en $1952^{9}$, y sobre el que realizó un pastel en 1978, titulado Pietà. El último Tiziano [fig. 4].

Sea como fuere, el amor de la madre relacionado con la vida y la muerte late en las asociaciones del río con la tumba y el regazo, como si en «El Tevere a su paso por Roma» hubiera una identificación entre el punto final de la tumba con el vientre de la madre, lugar del inicio de la vida, y como si la idea de retorno a un principio estuviera implícita en estas analogías. Es más, al llegar a Venecia escribió: «Yo no había venido a visitar esta ciudad, sino a tocarla, y no como una reliquia o una llaga dudosa, sino a tocarla como a un nido, como a un principio. Y para tocarla (...) necesitaba llegar hasta su centro, hasta su vientre materno» (2010: 35; las cursivas son de Gaya). La idea de principio en Gaya es una de las claves de su poética, como se puede apreciar en su entrevista con Andrés Trapiello en 1988: «Se trata de terminar esta vida y esta vocación en algo vivo, es decir, en algo completamente

\footnotetext{
8 Josefa Pomés era una mujer refinada y cultivada, hermana del escritor y periodista Ramón Pomés, que llegó a ser director del diario La Vanguardia. Las fuentes relativas a las circunstancias biográficas de Ramón Gaya provienen directamente del propio pintor, así como de su esposa Isabel Verdejo. Igualmente se pueden consultar en las entrevistas publicadas en Ramón Gaya de viva voz (2007), en Obra completa (2010: 957-966), así como en Miriam Moreno Aguirre, Otra modernidad. Estudios sobre la obra de Ramón Gaya (2018: 27-53). Por su parte, Andrés Trapiello ha ido haciendo a lo largo de los años acopio de sus conversaciones y relación personal con Ramón Gaya en Salón de pasos perdidos, el conjunto de sus diarios. Un resumen de esta amistad se puede consultar en Andrés Trapiello, Do fuir (2000: 111-113).

${ }_{9}$ «Uno de los Tiziano (La Pietà), aunque es de la última época, creo, es como Las Meninas, el trozo de pintura que más me ha impresionado. [...] La Virgen es una mujer ya bastante vieja, con un dolor tan maduro, tan firme, de piedra fría, de tan concentrado, de tan sabio». Véase Ramón Gaya, «Carta a Laurette Séjourné y Tomás Segovia», Venecia, 22 de julio de 1952, en Cartas a sus amigos (2016: 252-253; las cursivas son de Gaya).
} 


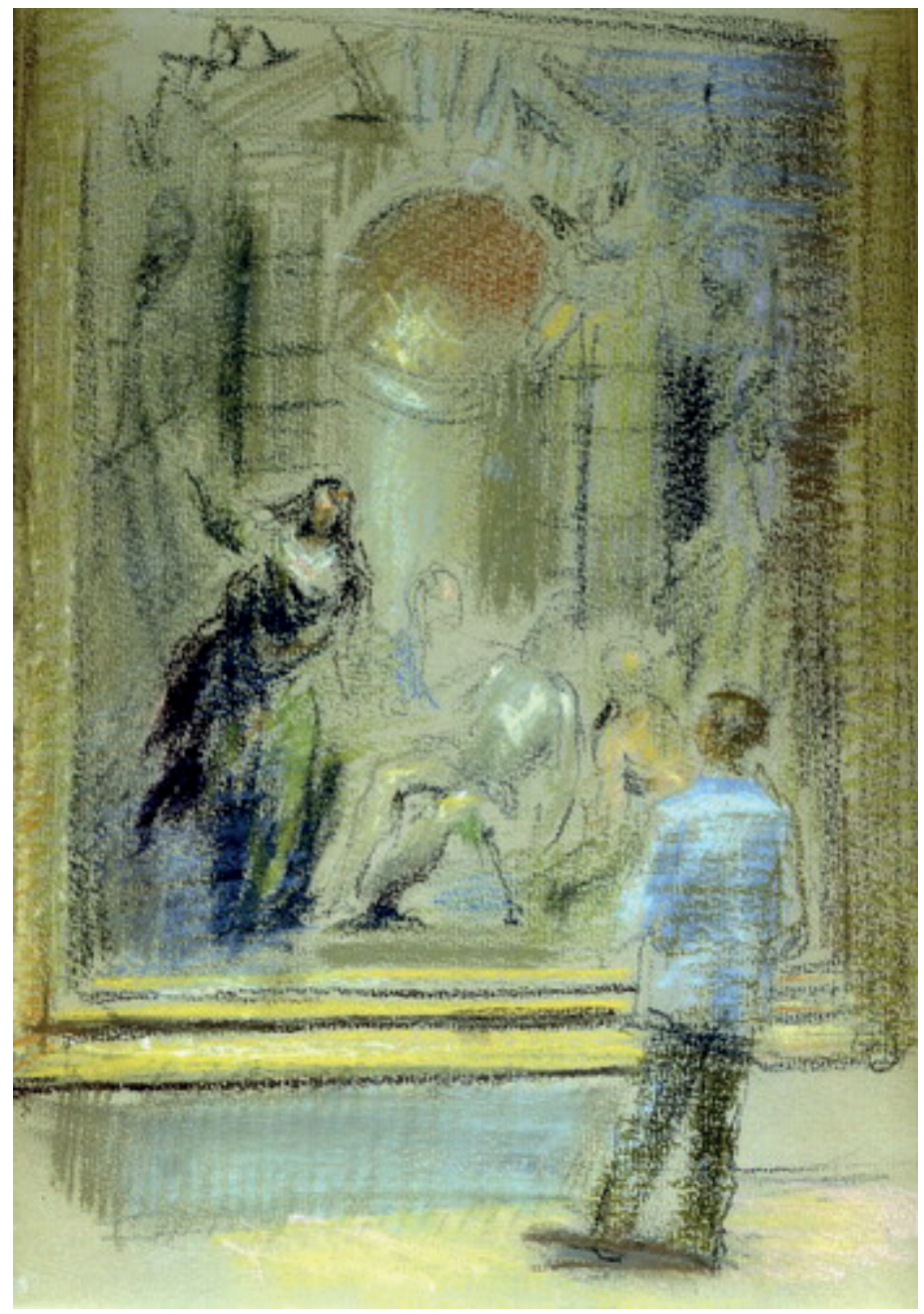

Fig. 4. Pietà. El último Tiziano (1978) [pastel]

original, naciente. Es decir, en vez de llegar a una maestría, donde hay que llegar es a un principio» (2007: 278). Y en El sentimiento de la pintura leemos: «Me parecía haber topado, al fin, con el manantial antiguo, femenino, tibio, húmedo, materno, de la pintura; un manantial que luego se abría y fluía en dos ramales» (2010: 39). La pintura, de nuevo asociada con el agua, brota de un manantial femenino y materno cuyo cauce se divide en dos brazos, como los ríos. Y de nuevo al final del mismo texto, una vez más la analogía entre el agua como elemento primordial y la madre: 
«El hombre artista-creador (...) es consciente de esa dificultad de encarnación en lo real, y solo entra en su espesura de bosque conducido por un brazo muy firme, casi materno, fundamental, elemental. Para el pintor, ese elemento conductor es... lo acuoso, que lentamente, parece ir deletreándole lo demás, lo total» (2010: 51; las cursivas son de Gaya). Aquí lo acuoso, asociado al brazo firme de la madre, es lo que guía al artista-creador que persigue la encarnación de lo real. Manantial, nido, regazo, vientre o matriz, lugar creador de vida, metáforas de un principio que Ramón Gaya anhelaba alcanzar.

Por otra parte, la acción o, mejor dicho, la no acción y el efecto de esperar, apenas sugeridos en la postura del retrato de la madre de Gaya, se hace patente en el caso de las figuras femeninas del Homenaje a Carpaccio, de 1951 [fig. 5].

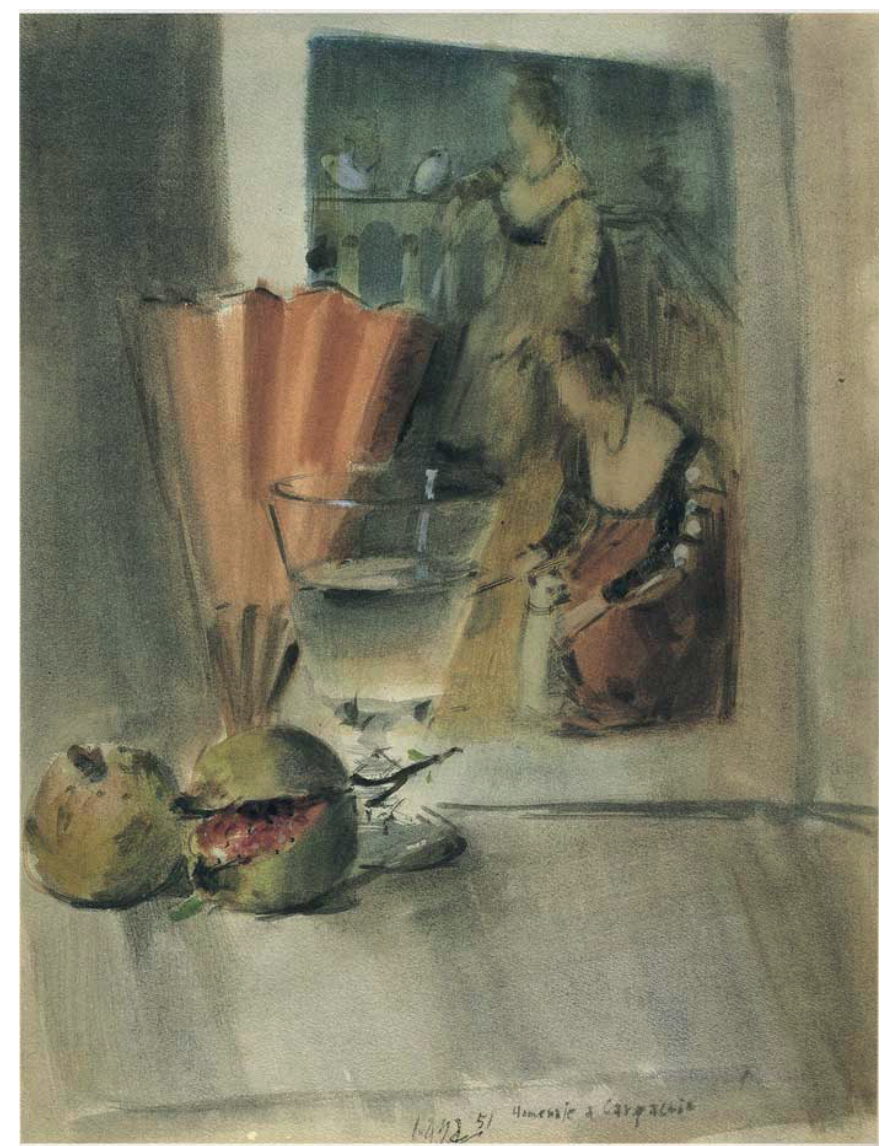

Fig. 5. Homenaje a Carpaccio (1951) [gouache] 
De este cuadro - del que conocía únicamente reproducciones, ya que no vio el original hasta su primera visita al Museo Correr en julio de $1952^{10}$, le atrae especialmente lo que él llama su «milagroso primitivismo poético» y el «saber vital» del vacío silencioso que sugiere el gesto perezoso de las damas venecianas, esa especie de apatía, melancolía o acedía, como si la espera fuera un motivo implícito en esta y en otras tantas obras a lo largo de la trayectoria de nuestro pintor, ya que la mujer sentada, a partir de la mencionada acuarela de 1927, aparece en, al menos, dieciséis obras. Entre estas cabe destacar de nuevo la imagen de Josefa Pomés, Mi madre. De un retrato de Miralles, de 1981, así como dos homenajes de 1994, realizados sobre el retrato de Rubens: Helena Fourment con sus hijos. La huella de la espera se puede reconocer igualmente en los cuadros de las prostitutas, un motivo que atraviesa la obra de Gaya desde sus comienzos en 1923. En la imagen de estas mujeres que parecen estar a la espera, cubiertas con apenas una bata o, sencillamente, desnudas, el pintor alude a una pasividad o despreocupación ociosa, melancólica, casi de aburrimiento, y cabría pensar que en ellas Gaya percibe, igual que en el cuadro veneciano de Carpaccio, «la historia profunda de un vacío» (2010: 37).

Ahora bien, el motivo de la espera adquiere un significado más específico cuando alude al estado anímico que precede a la mirada constituyente. Y el silencio de la espera es la renuncia al ruido del mundo y la búsqueda de la soledad necesaria para que un creador pueda hacer un hueco, una concavidad, un vacío en lo más íntimo suyo. Porque la quietud y el silencio de la espera es la condición de posibilidad o el requisito de la atención extrema que exige toda experiencia estética y toda contemplación. Entre 1956 y 1994 Ramón Gaya realiza más de veinticinco obras sobre el instante en que ciertos visitantes de un museo se aproximan a una obra maestra y la contemplan (Moreno, 2018: 165). En todos estos cuadros, como sucede en La Pietà. El último Tiziano, de 1978, el pintor capta con precisión el recogimiento y la receptividad del espectador ante el cuadro contemplado. La quietud y la calma reflejan ese estado de asombro o de pasmo que anuncia la contemplación, en la que se funden la atención extrema y la pasividad ${ }^{11}$. María Zambrano lo describe así:

Y este quedarse, que es quedarse en calma y en silencio -en el de dentro también-, supone un sobrepasar un cierto pasmo aceptándolo, que así en el pasmo sucede. El pasmo, en el que la conciencia se retrae apegándose al alma, juntándose con ella. Y entonces los sentidos se ensanchan, pues se llenan y se afinan, la mirada se sutiliza recorriendo el interior de esta presencia que es también su exterioridad, pues pintura es. [...] Y este estado

\footnotetext{
${ }^{10}$ Ramón Gaya, Diario de un pintor, Venecia, 2 de julio de 1952 (2010: 401).

${ }^{11}$ Gaya reflexionaba sobre la contemplación: «uno debe estar delante de la obra lo más despojado de sí mismo que pueda y recibir la obra, que la obra le llegue a él». Véase Ramón Gaya (2007: 224; las cursivas son de Gaya).
} 
de pasmo, en lo que tiene de extático, cede y se deshace, se resuelve en contemplación. [...] Contemplar es lo adecuado a lo que está vivo, porque es unidad en que se vierten la máxima vigilia de la conciencia y la pasividad del alma que acoge la realidad sin recelo (2012: 138-139).

En efecto, el rasgo común que vemos en todas estas pinturas de los visitantes en los museos es la inmovilidad de los contempladores ante los cuadros con una paciente quietud silenciosa, como si su admiración y asombro fueran tan extremados como un pasmo que deja en suspenso la razón, a la espera de recibir, acoger e interiorizar la realidad encarnada en la pintura, porque Gaya precisa que el espectador o la espectadora han de «acercarse a las obras de arte y esperar de ellas la devolución de ese secreto de la realidad» (2007: 363).

Rudolf Otto, a propósito del maestro Eckhart, estudia la metodología de la contemplación, según un escrito de Lutero titulado Cómo se ha de orar, donde el punto de partida es la espera, junto a la exigencia de «desembarazarse de cualquier asunto extraño» (2014: 291-292), con el fin de quedar totalmente libre para la meditación. De un modo parecido, Gaya indica que la contemplación sin ignorancia no tiene lugar, ya que la recepción de la obra no es posible si hay un esquema preconcebido (2007: 89) ${ }^{12}$. Por otra parte, Simone Weil, autora a la que le dedicó su trabajo de licenciatura Giorgio Agamben y de la que Gaya era un ferviente lector, concebía la atención como el acto de percepción estética por medio del cual los espectadores se unen al objeto de su contemplación, tras haber permanecido en la inmovilidad, a la espera. Weil consideraba la atención como una virtud al ser el estado previo y necesario de toda mirada creadora, cuyos rasgos son análogos a la contemplación místico-religiosa. Dicho con las palabras de la autora de La gravedad y la gracia: «la atención extrema es lo que constituye en el hombre la facultad creadora, y no hay atención extrema que no sea religiosa» (1994: 125). La atención es principalmente un estado receptivo que consiste en dejar el hueco para que las cosas entren, lo que exige de una espera paciente asociada a una suspensión de la actividad mental, y dejando un vacío que, como asegura Weil, está íntimamente relacionado con la gracia, ya que: «la gracia colma, pero no puede entrar más que allá donde hay un vacío para recibirla, y es ella la que hace ese vacío» (1994: 31).

Por tanto, la espera silenciosa es el estado anímico necesario para alcanzar esa atención extrema y la receptividad que Gaya asocia también con la pasividad, el abstenerse de hacer o la mansedumbre. Así lo indica en el soneto titulado precisamente «Mansedumbre de obra», de 1978 (2010: 635-636; las cursivas son mías):

${ }_{12}$ En El sentimiento de la pintura el pintor afirma que se trata de una «ignorancia viva», «sabiduría primera» o «voz de origen» (2010: 34$)$. 
Acude entero el ser, y, más severa, también acude el alma, si el trazado, ni justo ni preciso, ha tropezado, de pronto, con la carne verdadera.

Pintar no es acertar a la ligera, ni es tapar, sofocar, dejar cegado ese abismo que ha sido encomendado a la sed y al silencio de la espera.

Lo pintado no es nada: es una cita -sin nosotros, sin lienzo, sin pinturaentre un algo escondido y lo aparente.

Si todo, puntual, se precipita, la mano del pintor -su mano impurano se afana, se aquieta mansamente.

La mansedumbre es, en efecto, una receptividad pasiva que se da en medio de la calma serena, silenciosa, paciente y madura del que espera, tal como dice maravillosamente Eloy Sánchez Rosillo en estos versos de su poema «La Espera» (1980: 24): «Y vaga por el cuarto, / decidido a esperar a que madure el tiempo / en que la viva realidad que ansía, / dulcemente, sin lucha, se le entregue».

A la sed y al silencio de la espera les ha sido encomendado un abismo, un vacío. En 1945 Ramón Gaya había escrito en «Homenaje a Velázquez»: «el arte es un vacío, un sitio, un lugar al que se asoma el ser humano no para comprender las cosas y comprenderse, sino para sentirse [...]. Porque el arte no es, como se pensó, una corporeidad, sino una concavidad» (2010: 60; las cursivas son mías). Un lugar para sentirse, un vacío, una concavidad. Leonardo Cammarano nos ayuda a descifrar la noción gayesca de concavidad, a partir de la distinción entre el yo creador y el yo empírico. Para Cammarano el primero es el «yo cóncavo» e intensivo y el segundo, el «yo convexo» o extensivo (2008: 29-30). Por consiguiente, la concavidad, según este autor, es la condición de la creación: «Una concavidad de silencio. En un momento he podido creer que eso era el arte. (Y lo es en definitiva), pero una concavidad de silencio es en realidad lo vivo. El arte, si es vivo, participa de esa condición» (2010: 579; las cursivas son mías). Además, para Gaya concavidades pueden ser tanto la música como una escultura, incluso el lienzo y la obra misma. También un pozo, una cueva, un nido, un regazo maternal, la naturaleza en su totalidad o, sencillamente, 
un paisaje, la ciudad de Venecia o una copa de cristal. La concavidad, ese hueco vacío como la palma de la mano del mendigo, como la mano vacante del pintor que espera sin hacer nada, en silencio, a que acuda la realidad viva. Ciertamente, como observa con acierto Eduardo Chamorro (2011), la expresión «concavidad de silencio» condensa lo esencial del pensamiento de Gaya sobre el arte, en el que la imagen de la «concavidad» es una metáfora, una imagen matriz y un hilo conductor de su universo simbólico. Así lo expone el propio pintor: «Ese misterio, ese secreto que yo quisiera recoger en mi pintura, mejor dicho en mi obra -literaria o pictórica-, no se puede desvelar nada más que con la metáfora» (2007: 213).

Según Ortega y Gasset (2002), el metaforizar consiste en la trasposición de una cosa desde su lugar real a su lugar sentimental, que es el que confiere a un poema el carácter de profundidad y de intimidad. Con este mecanismo, observa el filósofo, se perturba nuestra visión natural de las cosas, de tal modo que aflora una nueva interpretación sentimental como una operación que supera la estructura real de las cosas al desrealizar, captando algo que de ordinario nos pasa inadvertido. Ese algo es el valor sentimental de las cosas. La metáfora desrealiza, lo que dicho en el lenguaje gayesco sería que la metáfora salva lo real al captar un «algo» que no percibimos en la vida ordinaria y ese «algo» es lo que Gaya llama el misterio de la realidad. No obstante, la metáfora, para el pintor, no expresa, sino que borra: «La metáfora no quiere, en absoluto, caracterizar, expresar, y claro, mucho menos aún, adornar la realidad, sino borrar en ésta todo lo externo, lo aparente, y que pueda surgir entonces, ya sin trabas, lo suyo más recóndito» (2010: 494). Cabría decir, por tanto, que la metáfora es el puente entre ese "algo escondido y lo aparente», un puente entre lo invisible y lo visible, por su virtualidad de un borrar que no es expresión sino silencio. Así lo dejó escrito Gaya: «Pero todo eso otro vendrá siempre dicho con una voz tan queda -en una voz, diríamos, de imagen, en una voz de metáfora-, en una voz que no es voz, sino visión, casi como una silenciosidad» (2010: 233). La metáfora es la voz de imagen, es silencio y es, además, el puente o el abrazo que reúne pintura y poesía en la obra de Ramón Gaya.

\section{Bibliografía}

Agamben, Giorgio, «El lugar de la poesía. Aproximaciones a la poesía de Ramón Gaya», traducción de Tomás Segovia, en VV. AA., catálogo de la exposición Ramón Gaya. La hora de la pintura, julio-septiembre de 2006, La Pedrera, Barcelona, Fundació Caixa Catalunya, 2006, págs. 49-57.

Agamben, Giorgio, Autoritratto nello studio, Nottetempo, Milano, 2017, págs. 18-19. 
Bachelard, Gaston, La poética de la ensoñación, traducción de Ida Vitale, Fondo de Cultura Económica, 2002.

Bachelard, Gaston, El agua y los sueños, traducción de Ida Vitale, Fondo de Cultura Económica, 2002.

Bonet, Juan Manuel, Una copa de agua, Murcia, Museo Ramón Gaya/Fundación Santander Central Hispano, 2005.

Cammarano, Leonardo, «Gaya, l'eleganza del realismo / Gaya, la elegancia del realismo». «Il problema dell'eleganza / El problema de la elegancia», traducción de Isabel Verdejo, en VV.AA., catálogo de la exposición antológica de Ramón Gaya, Murcia, Instituto Cervantes de Nápoles / Museo Ramón Gaya, 2008, págs. 19-34.

Chamorro Romero, Eduardo, «Contemplación artística y escucha analítica. A propósito de Velázquez, pájaro solitario de Ramón Gaya», en VV.AA., Escritura e imagen, vol. 7, Homenaje a Ramón Gaya en su centenario (1910-2010), Madrid, Publicaciones de la Universidad Complutense de Madrid, 2011, págs. 77-98.

Durante, Laura Mariateresa, Ramón Gaya. El exilio de un creador, Roma, Edizioni Nuova Cultura, 2013.

Gaya, Ramón, Il sentimento della pittura, traducción de Leonardo Cammarano, Roma, De Luca Editore, 1960a.

Gaya, Ramón, Catálogo de la exposición celebrada en el mes de abril, Galería Mayer, Madrid, 1960b.

Gaya, Ramón, El sentimiento de la pintura, Madrid, Ediciones Arión, 1960c.

Gaya, Ramón, Velázquez, pájaro solitario, Barcelona, RM, 1969.

Gaya, Ramón, «Velazquez passero solitario», Conoscenza Religiosa, Florencia, n. ${ }^{\circ}$ 1, 1971, págs. 64-79.

Gaya, Ramón, Naturalidad del arte (y artificialidad de la crítica), Valencia, PreTextos, 1996.

Gaya, Ramón, Ramón Gaya de viva voz. Entrevistas 1977-1998, selección y presentación de Nigel Dennis, Valencia, Pre-Textos, 2007.

Gaya, Ramón, Obra completa, edición al cuidado de Nigel Dennis e Isabel Verdejo, prólogo de Tomás Segovia, Valencia, Pre-Textos, 2010.

Gaya, Ramón, Il sentimento della pittura, traducción de Laura Mariateresa Durante, presentación de Ana María Leyra, Chieti, Solfanelli, 2015.

Gaya, Ramón, Cartas a sus amigos, edición al cuidado de Nigel Dennis e Isabel Verdejo, prólogo de Andrés Trapiello, Valencia, Pre-Textos, 2016.

Gaya, Ramón y Zambrano, María, Y así nos entendimos. María Zambrano - Ramón Gaya (Correspondencia 1949-1990), edición al cuidado de Isabel Verdejo y Pedro chacón, epílogo de Laura Mariateresa Durante, Valencia, Pre-Textos, 2018. 
Moreno Aguirre, Miriam, Otra modernidad. Estudios sobre la obra de Ramón Gaya, Valencia, Pre-Textos y Fundación Amado Alonso, 2018.

Muñoz Millanes, José, La Venecia de Ramón Gaya, Murcia, Museo Ramón Gaya, 2015.

Ortega y Gasset, José, «Ensayo de estética a manera de prólogo», en La deshumanización del arte y otros ensayos de estética, prólogo de Valeriano Bozal, Madrid, Espasa Calpe, 2002, págs. 151-158.

Otto, Rudolf, Mística de Oriente y Occidente. Sánkara y Eckhart, traducción y notas de Manuel Abella, Madrid, Trotta, 2014.

Sánchez Rosillo, Eloy, «La espera», Homenaje a Ramón Gaya, Editora Regional de Murcia, 1980, p. 24.

Trapiello, Andrés, Do fuir, Valencia, Pre-Textos, 2000, págs. 111-113.

Weil, Simone, La gravedad y la gracia, traducción de Jesús Pendás, Benito y Alejandro del Río Herrmann, Madrid, Caparrós editores, 1994.

Zambrano, María, «La pintura en Ramón Gaya», Ínsula, n. ${ }^{\circ}$ 100, Madrid, 1960, págs. 3 y 7. Véase también Algunos lugares de la pintura, edición revisada y notas de Pedro Chacón, Madrid, Eutelequia, 2012, págs.136-144. 